\title{
Systematic review and meta-analysis of early postnatal dexamethasone for prevention of chronic lung disease
}

\author{
Tushar Bhuta, Arne Ohlsson
}

\begin{abstract}
Aim-To review systematically the evidence to determine whether dexamethasone treatment of very low birthweight infants begun within 14 days of age prevents chronic lung disease (CLD) without clinically significant side effects.

Methods-Randomised controlled trials of dexamethasone started within this time frame were identified through a search of electronic databases, proceedings of scientific meetings, and personal files. Metaanalyses using event rate ratio (ERR), event rate difference (ERD), and if significant, numbers needed to treat (NNT) for benefits and numbers needed to harm (NNH) for adverse effects were calculated. Weighted mean difference were used for continuous variables. Three prespecified subgroup analyses were performed for; (i) dexamethasone begun within 36 hours (hours) of birth; (ii) dexamethasone initiated between 7-14 days of age; or (iii) if surfactant treatment was used.
\end{abstract}

Results-Ten studies were included in the review; six where dexamethasone was initiated within 36 hours of age, four studies for dexamethasone started between 7 and 14 days and six studies using surfactant. Mortality ERR and NNT with $95 \%$ confidence intervals for dexamethasone initiated at 7-14 days of age were $0.35(0.16$, $0.74)$ and $8(4,30)$. ERRs and NNTs for CLD at 28 days and 36 weeks of postmenstrual age were $0.71(0.61,0.84), 8(5,17)$, and $0.57(0.44,0.76), 10(6,23)$ in the overall analyses. When dexamethasone was started at 7 to 14 days of age ERR and NNT for CLD at 36 weeks were $0.63(0.47,0.85)$ and $3(2,9)$. Clinically significant side effects included increased risk of hypertension, hyperglycaemia, and increased time to regain birthweight.

Conclusions-These meta-analyses show a significant reduction in risk of CLD at 28 days and 36 weeks of postmenstrual age. In the subgroup where dexamethasone was started between 7 and 14 days of age mortality was significantly reduced. Caution is warranted in the routine use of dexamethasone because of lack of data on long term neurodevelopmental outcomes. (Arch Dis Child Fetal Neonatal Ed 1998;79:F26-F33)

Keywords: dexamethasone; chronic lung disease; prevention; meta-analysis; randomised controlled trials
Routine use of surfactant replacement for respiratory distress syndrome (RDS) has reduced the incidence of pneumothoraces in premature infants. ${ }^{1-3}$ However, multicentre trials have failed to show a reduction in the incidence of chronic lung disease (CLD). ${ }^{4-6}$ The combined use of antenatal steroids and postnatal surfactant replacement significantly decreased the overall morbidity and mortality caused by RDS relative to either treatment alone. ${ }^{7}$

Steroids have been used in several controlled trials to treat established CLD and have shown significant short term improvements in lung function. ${ }^{8-12}$ Postulated mechanisms by which steroids might improve lung function include increased surfactant synthesis, inhibition of prostaglandins and leucotriene synthesis, enhancement of $\beta$ adrenergic activity and reduced pulmonary oedema. ${ }^{13}$ Cellular and biochemical studies have shown inflammatory changes in the lungs of ventilated infants ${ }^{14-16}$ as early as the first few days of life and dexamethasone has been shown to reduce this inflammation. ${ }^{17}{ }^{18}$ But there is still concern over the potential side effects of dexamethasone in preterm neonates. ${ }^{19-25}$

In view of the conflicting results of the effectiveness of early postnatal dexamethasone for the prevention of CLD and the small number of patients in some of these trials, we undertook a systematic review and metaanalyses of the results of these trials.

\section{Methods}

A search was undertaken with the use of three databases: MEDLINE (National Library of Medicine) for the years 1980-97, EMBASE for the years 1989-96, and the Oxford Database of Perinatal Trials (ODPT). The Proceedings of American Pediatric Society/Society of Pediatric Research meeting abstract books from the years 1991-6 were searched manually. Further studies were identified from reference lists of publications noted above. To be included in the review, trials had to meet each of the following criteria:

(1) randomised controlled trial

(2) the study infants were newborns with a birthweight of $2000 \mathrm{~g}$ or less

(3) the intervention was dexamethasone

(4) dexamethasone was started within 14 days of birth

(5) dexamethasone was electively started for prevention of CLD

(6) the study included some measure of some of the following outcomes 
Mortality

CLD at 28 days

CLD at 36 weeks of postmenstrual age

Days in supplemental oxygen

Days in hospital

Days on mechanical ventilation

Days to regain birthweight

Hypertension defined as systolic or diastolic blood pressure $>2 \mathrm{SD}$ above mean values $^{26}$

Sepsis

Intraventricular haemorrhage (IVH) any grade

Intraventricular haemorrhage (grades 3 or 4)

Necrotising enterocolitis (NEC)

Retinopathy of prematurity (ROP) any stage

Hyperglycaemia defined as greater than $8.3 \mathrm{mmol} / 1$

Insulin for hyperglycaemia

Air leak syndromes

Long term pulmonary and neurodevelopmental follow up

This review used the guidelines of the Cochrane Collaboration as outlined in the Cochrane Library ${ }^{27}$ and the Effective Care of the Newborn Infant. ${ }^{28}$ The data were extracted separately by each author and then compared. A third data extraction and discussion resolved discrepancies. Additional information was sought from the authors when required. The data taken from abstracts were compared with data taken from the full manuscripts by the same author(s) where possible to try and avoid inclusion of duplicate data. Meta-analyses of dichotomous outcomes were expressed in three ways. The event rate ratio (ERR), event rate difference (ERD), and if significant, numbers needed to treat (NNT) for benefits and
Key messages

- Early postnatal dexamethasone begun within 14 days of age significantly reduces the risk of CLD at 28 days and 36 weeks of postmenstrual age

- When started between 7 and 14 days of age there is also a significant reduction in mortality.

- Significant side effects include increased risk of hypertension, hyperglycaemia, and increased time to regain birthweight

- There are no data on long term neurodevelopmental outcomes

numbers needed to harm (NNH) for adverse effects were calculated (95\% confidence intervals were used for all the analyses). Continuous data were expressed as a mean difference and weighted mean difference in the meta-analyses. Heterogeneity between the trial results was assessed for significant outcomes. The data were synthesised using Meta-Analyser, version 1.2 (Update software Ltd).

For these analyses the authors chose to base validity assessment on four methodological criteria that can be associated with significant bias in trials assessing treatment effect, ${ }^{29}$ and these were evaluated separately by each author. These included concealment at randomisation, blinding of treatment, blinding of outcome assessment and completeness of follow up. No scoring system is incorporated in this particular method of evaluation. The final assessment of the validity of the studies included is therefore left to the individual reader.

Three subgroup analyses were determined a priori. Two subgroups were based on the time

Table 1 Characteristics of trials included in the review: trials where dexamethasone has begun $<36$ hours of age

\begin{tabular}{|c|c|c|c|c|c|c|c|}
\hline Author & Year & $\begin{array}{l}\text { Double } \\
\text { blinded }\end{array}$ & Dose (mg/kg/day) & $\begin{array}{l}\text { Course } \\
\text { (days) }\end{array}$ & Start age & $\begin{array}{l}\text { No of } \\
\text { patients }\end{array}$ & Characteristics \\
\hline Rastogi et $a l^{30}$ & 1996 & Yes & $0.5(3), 0.3(3),{ }^{\star} 0.2(3), 0.1(3)$ & 12 & $<12 \mathrm{~h}$ & 64 & $\begin{array}{l}700-1500 \mathrm{~g} \text {; stratified } 700-999 \mathrm{~g}, 1000-1249 \mathrm{~g} \\
1250-1500 \mathrm{~g} \text {; surfactant, } \mathrm{MV}, 13 \% \text { in dex and } \\
47 \% \text { in control received steroids }\end{array}$ \\
\hline Shinwell et $a l^{\beta 1}$ & 1996 & Yes & $0.5(3)$ & 3 & $<12 \mathrm{~h}$ & 248 & $\begin{array}{l}500-2000 \mathrm{~g} \text {; stratified } 500-1000 \mathrm{~g}, 1001-2000 \mathrm{~g} \\
\text { surfactant, } \mathrm{MV}, 27 \% \text { in dex and } 26 \% \text { in } \\
\text { control received steroids }\end{array}$ \\
\hline Sander $e t a l^{32}$ & 1994 & Yes & 1 (1) & 1 & $12-18 \mathrm{~h}$ & 40 & $\begin{array}{l}<30 \mathrm{w} \text { GA; MV at } 12-18 \mathrm{~h} \text {; surfactant } 10 \% \text { in } \\
\text { dex and } 14 \% \text { in control received steroids }\end{array}$ \\
\hline Yeh $e t a l^{33}$ & 1990 & Yes & 1 (3),0.5(3),0.25(3),0.1(3) & 12 & $<12 \mathrm{~h}$ & 60 & $\begin{array}{l}\text { 700-1999 g; stratified <1000 g; } 1001-1500 \mathrm{~g} ; 3 \\
\text { excluded; MV }\end{array}$ \\
\hline Tapia $e t a l^{39}$ & 1996 & Yes & $0.5(3), 0.3(3), 0.2(3), 0.1(3)$ & 12 & $<36 \mathrm{~h}$ & 109 & $700-1600 \mathrm{~g}, \mathrm{MV}$; surfactant \\
\hline Yeh $e t a l^{8}$ & 1994 & Yes & $0.5(7), 0.25(7), 0.1(7), 0.05(7)$ & 28 & $<12 \mathrm{~h}$ & 142 & $<2000$ g; MV \\
\hline
\end{tabular}

^Figures in parentheses indicate number of days. $M V=$ mechanically ventilated; $d e x=$ dexamethasone.

Table 2 Characteristics of trials included in the review: trials where dexamethasone has begun 7-14 days of age

\begin{tabular}{|c|c|c|c|c|c|c|c|}
\hline Author & Year & $\begin{array}{l}\text { Double } \\
\text { blinded }\end{array}$ & Dose (mg/kg/day) & $\begin{array}{l}\text { Course length } \\
\text { (day) }\end{array}$ & Start age & $\begin{array}{l}\text { No of } \\
\text { patients }\end{array}$ & Characteristics \\
\hline Durand $e t a l^{34}$ & 1995 & No & $0.5(3), 0.25(3), 0.1(3)$ & 7 & $7-14 \mathrm{~d}$ & 43 & $\begin{array}{l}501-1500 \mathrm{~g} ; 24-32 \mathrm{w} ; \mathrm{MV} \text { at } 7-14 \\
\mathrm{~d} \text {; surfactant } 26 \% \text { in dex and } \\
65 \% \text { in control received steroids }\end{array}$ \\
\hline Brozanski et $a l^{35}$ & 1995 & Yes & $\begin{array}{l}0.5 \text { (3) every } 10 \text { days, until } \star 36 \text { w PMA or no } \mathrm{O}_{2} \\
\text { therapy }\end{array}$ & $\begin{array}{l}\text { Until } 36 \mathrm{w} \\
\text { PMA }\end{array}$ & $7 \mathrm{~d}$ & 78 & $\begin{array}{l}<1500 \mathrm{~g} ; \text { stratified }<1000,>1001 \\
\quad \text { surfactant; } \text { MV No crossover }\end{array}$ \\
\hline Kari et $a l^{36}$ & 1993 & Yes & $0.5(7)$ & 7 & $10 \mathrm{~d}$ & 41 & $\begin{array}{l}<1500 \mathrm{~g} ;>24 \mathrm{w} ; \mathrm{MV} \text { at } 10 \text { days; } \\
\text { only } 3 \text { patients in in dex group } \\
\text { and } 1 \text { control received surfactant } \\
33 \% \text { of controls received steroids }\end{array}$ \\
\hline \multirow{2}{*}{$\underset{a l^{37}}{\text { Cummings et }}$} & \multirow[t]{2}{*}{1989} & \multirow[t]{2}{*}{ Yes } & \multirow{2}{*}{$\begin{array}{l}0.5 \text { (3), } 0.3 \text { (3), then } \downarrow \text { by } 10 \% \text { every } 3 \text { days until } \\
0.1 \text { and then on alternate days for } 1 \text { week }\end{array}$} & 42 & \multirow[t]{2}{*}{$14 \mathrm{~d}$} & \multirow[t]{2}{*}{36} & \multirow{2}{*}{$\begin{array}{l}<1250 \mathrm{~g} ;<30 \mathrm{w} ; \mathrm{MV} \text { at } 14 \text { days; } \\
\text { randomised to three groups, } 42 \\
\text { d, } 18 \mathrm{~d} \text {, and control }\end{array}$} \\
\hline & & & & 18 & & & \\
\hline
\end{tabular}

Figures in parentheses indicate days. PMA = post menstrual age; dex = dexamethasone. 
Table 3 Validity of trials included in the review

\begin{tabular}{|c|c|c|c|c|c|}
\hline Author & Year & Method of randomisation & $\begin{array}{l}\text { Blinding of } \\
\text { intervention }\end{array}$ & $\begin{array}{l}>90 \% \text { Follow } \\
\text { up }\end{array}$ & $\begin{array}{l}\text { Blinding of } \\
\text { outcomes }\end{array}$ \\
\hline Rastogi et $a l^{\beta 0}$ & 1996 & Phone/coded drugs & Yes & Yes & Yes \\
\hline Shinwell et $a l^{\beta 1}$ & 1996 & Phone/coded drugs & Yes & Yes & Yes \\
\hline Sander $e t a l^{2}$ & 1994 & Sealed envelopes/coded drugs & Yes & Yes & Yes \\
\hline Yeh et $a l^{33}$ & 1990 & Assigned list by pharmacy & Yes & Yes & Yes \\
\hline Tapia $e t a l^{9}$ & 1996 & Not described & Yes & Yes & Yes \\
\hline Yeh $e t a l^{88}$ & 1994 & Not described & Yes & Yes & ? \\
\hline Durand $e t a l^{4}$ & 1995 & Sealed envelopes & No & Yes & Yes \\
\hline Brozanski et $a l^{35}$ & 1995 & Sealed envelopes & Yes & Yes & Yes \\
\hline Kari et $a l^{36}$ & 1993 & Not described & Yes & Yes & ? \\
\hline Cummings et $a l^{37}$ & 1989 & Assigned list/coded drugs & Yes & Yes & Yes \\
\hline
\end{tabular}

of postnatal initiation of dexamethasone. In the first subgroup all the studies in which dexamethasone was started within 36 hours of postnatal age were included and in the second subgroup were those studies which started dexamethasone between 7 and 14 days of postnatal age. The third subgroup consisted of all studies where surfactant replacement was used in addition to dexamethasone.

Sensitivity analyses were done to look at the effectiveness of different doses and duration of dexamethasone treatment.

\section{Results}

Ten studies were selected for inclusion in the review, eight of which were full publications ${ }^{30-37}$; two were abstracts at the time of the review. ${ }^{38} 39$ One of the abstracts was in the process of being submitted for publication. Additional information was sought from the authors of these abstracts and also of the published studies as required. The characteristics of the trials, as reported, are summarised in tables 1 and 2 .

Most of the trials allowed for open treatment with dexamethasone at the discretion of the clinician after the treatment period. Only ventilator dependent patients were randomised in all trials.
The study design of each trial is shown in table 3. Of the 10 trials reviewed in this systematic review, in nine the intervention was blinded and in eight the outcomes were blinded; all the trials having more than $90 \%$ follow up.

MORTALITY

There was no significant difference (table 4 ) in mortality in the neonates randomised to dexamethasone in the overall analyses, the subgroups where dexamethasone was started within 36 hours of age (table 5), and the subgroup where surfactant was administered ${ }^{30}$ 37-39 [ERR 0.98 $(0.70,1.36)]$. However, in the subgroup analyses where dexamethasone was started within 7 to 14 days of postnatal age (table 5) there was a significant reduction in mortality [ERR 0.35 $(0.16,0.74)$, NNT $8(4,30)]$. This suggests that on average eight infants would need to be treated with dexamethasone between 7 to 14 days of postnatal age to prevent one death. There was no significant heterogeneity between the results of the trials.

CHRONIC LUNG DISEASE AT 28 DAYS

In the overall ${ }^{31}$ 33-36 3839 (table 6) and all three subgroup analyses there was a significant reduction in CLD in the neonates given

Table 4 Effect of dexamethasone on mortality: all trials

\begin{tabular}{|c|c|c|c|c|c|c|c|c|}
\hline Trials & Year & $\begin{array}{l}\text { Expected } \\
\text { observed }\end{array}$ & $\begin{array}{l}\text { Expected } \\
\text { total }\end{array}$ & $\begin{array}{l}\text { Controls } \\
\text { observed }\end{array}$ & $\begin{array}{l}\text { Controls } \\
\text { total }\end{array}$ & $E R R(95 \% C I)$ & $E R D(95 \% C I)$ & NNT $(95 \% C I)$ \\
\hline$\overline{\text { Durand } e t a l^{4}}$ & 1995 & 2 & 23 & 4 & 20 & $0.43(0.08,2.37)$ & $-11.30(-32.28,9.67)$ & \\
\hline Brozanski et $a l^{35}$ & 1995 & 2 & 39 & 9 & 39 & $0.22(0.05,1.03)$ & $-17.95(-32.87,-3.02)$ & \\
\hline Yeh et $a l^{38}$ & 1994 & 28 & 75 & 20 & 67 & $1.25(0.70,2.22)$ & $7.40(-8.01,22.97)$ & \\
\hline Cummings et $a b^{77}$ & 1989 & 3 & 12 & 6 & 11 & $0.46(0.11,1.83)$ & $-29.55(-67.84,8.74)$ & \\
\hline Kari et $a l^{6}$ & 1993 & 1 & 17 & 3 & 24 & $0.24(0.01,4.70)$ & $-6.62(-23.94,10.71)$ & \\
\hline Shinwell et $a l^{31}$ & 1996 & 31 & 132 & 22 & 116 & $1.24(0.72,2.14)$ & $4.52(-5.64,14.68)$ & \\
\hline Rastogi et $a l^{30}$ & 1996 & 4 & 36 & 2 & 34 & $1.89(0.35,10.31)$ & $5.23(-7.73,18.19)$ & \\
\hline Sander et $a l^{32}$ & 1994 & 2 & 19 & 7 & 21 & $0.32(0.07,1.52)$ & $-22.81(-47.24,1.63)$ & \\
\hline Tapia et a $\beta^{99}$ & 1996 & 17 & 55 & 18 & 54 & $0.93(0.48,1.80)$ & $-2.42(-19.95,15.10)$ & \\
\hline Yeh et $a B^{33}$ & 1990 & 3 & 28 & 8 & 29 & $0.39(0.10,1.46)$ & $-16.87(-36.77,3.02)$ & \\
\hline Pooled $\left[\chi^{2} 14.00(\mathrm{df}=9)\right]$ & & 93 & 436 & 98 & 415 & $0.88(0.69,1.13)$ & $-3.44(-8.57,1.68)$ & \\
\hline
\end{tabular}

Table 5 Effect of dexamethasone on death

\begin{tabular}{|c|c|c|c|c|c|c|c|c|}
\hline Trials & Year & $\begin{array}{l}\text { Expected } \\
\text { observed }\end{array}$ & $\begin{array}{l}\text { Expected } \\
\text { total }\end{array}$ & $\begin{array}{l}\text { Controls } \\
\text { observed }\end{array}$ & $\begin{array}{l}\text { Controls } \\
\text { total }\end{array}$ & $E R R(95 \% C I)$ & $E R D(95 \% C I)$ & NNT $(95 \% C I)$ \\
\hline \multicolumn{9}{|l|}{ When begun at $<36 h$ of age: } \\
\hline Yeh $e t a l^{88}$ & 1994 & 28 & 75 & 20 & 67 & $1.25(0.70,2.22)$ & $7.48(-8.01,22.97)$ & \\
\hline Shinwell et $a l^{11}$ & 1996 & 31 & 132 & 22 & 116 & $1.24(0.72,2.14)$ & $4.52(-5.64,14.68)$ & \\
\hline Rastogi et $a l^{30}$ & 1996 & 4 & 36 & 2 & 34 & $1.89(0.35,10.31)$ & $5.23(-7.73,18.19)$ & \\
\hline Sander $e t a \beta^{2}$ & 1994 & 2 & 19 & 7 & 21 & $0.32(0.07,1.52)$ & $-22.81(-47.24,1.63)$ & \\
\hline Tapia et $a l^{39}$ & 1996 & 17 & 55 & 18 & 54 & $0.93(0.48,1.80)$ & $-2.42(-19.95,15.10)$ & \\
\hline Yeh et a ${ }^{33}$ & 1990 & 3 & 28 & 8 & 29 & $0.39(0.10,1.46)$ & $-16.87(-36.77,3.02)$ & \\
\hline Pooled $\chi^{2}=6.92(\mathrm{df}=5)$ & & 83 & 345 & 77 & 321 & $1.03(0.78,1.34)$ & $0.64(-5.42,6.69)$ & \\
\hline \multicolumn{9}{|c|}{ Subgroup when begun between $7-14$ days of age: } \\
\hline Durand $e t a l^{34}$ & 1995 & 20 & 23 & 4 & 20 & $0.43(0.08,2.37)$ & $-11.30(-32.28,9.67)$ & \\
\hline Brozanski et a $p^{5}$ & 1995 & 2 & 39 & 9 & 39 & $0.22(0.05,1.03)$ & $-17.95(-32.87,-3.02)$ & \\
\hline Cummings et al ${ }^{37}$ & 1989 & 3 & 12 & 6 & 11 & $0.46(0.11,1.83)$ & $-29.55(-67.84,8.74)$ & \\
\hline Kari et $a l^{\overline{6}}$ & 1993 & 1 & 17 & 3 & 24 & $0.24(0.01,4.70)$ & $-6.62(-23.94,10.71)$ & \\
\hline Pooled $\left[\chi^{2}=0.94(\mathrm{df}=3)\right]$ & & 8 & 91 & 21 & 94 & $0.35(0.16,0.74)$ & $-12.13(-20.97,-3.29)$ & $8(4,30)$ \\
\hline
\end{tabular}


Table 6 Effect of dexamethasone on CLD at 28 days: all trials

\begin{tabular}{|c|c|c|c|c|c|c|c|c|}
\hline Trials & Year & $\begin{array}{l}\text { Expected } \\
\text { observed }\end{array}$ & $\begin{array}{l}\text { Expected } \\
\text { total }\end{array}$ & $\begin{array}{l}\text { Controls } \\
\text { observed }\end{array}$ & $\begin{array}{l}\text { Controls } \\
\text { total }\end{array}$ & $E R R(95 \% C I)$ & $E R D(95 \% C I)$ & NNT $(95 \% C I)$ \\
\hline Durand $e t a l^{34}$ & 1995 & 7 & 22 & 13 & 19 & $0.47(0.19,1.17)$ & $-36.60(-65.16,-8.04)$ & \\
\hline Brozanski et $a l^{35}$ & 1995 & 33 & 37 & 31 & 32 & $0.92(0.56,1.50)$ & $-7.69(-19.37,4.00)$ & \\
\hline Yeh $e t a l^{88}$ & 1994 & 11 & 47 & 24 & 47 & $0.46(0.22,0.94)$ & $-27.66(-46.39,-8.93)$ & \\
\hline Kari et $a b^{6}$ & 1993 & 15 & 17 & 21 & 22 & $0.92(0.48,1.79)$ & $-7.22(-24.84,10.40)$ & \\
\hline Shinwell et $a l^{31}$ & 1996 & 32 & 132 & 24 & 116 & $1.17(0.69,1.99)$ & $3.55(-6.83,13.94)$ & \\
\hline Rastogi et $a l^{30}$ & 1996 & 5 & 32 & 21 & 32 & $0.24(0.09,0.63)$ & $-50.00(-70.71,-29.29)$ & \\
\hline Tapia et $a l^{39}$ & 1996 & 11 & 55 & 16 & 54 & $0.68(0.31,1.45)$ & $-9.63(-25.76,6.50)$ & \\
\hline Yeh et $a l^{\beta 3}$ & 1990 & 8 & 26 & 12 & 20 & $0.51(0.21,1.25)$ & $-29.23(-57.08,-1.38)$ & \\
\hline $\begin{array}{l}\text { Pooled }\left[\chi^{2}=37.94\right. \\
\quad(\mathrm{df}=7)]\end{array}$ & & 122 & 368 & 62 & 342 & $0.71(0.61,0.84)$ & $-11.53(-17.17,-5.88)$ & $8(5,17)$ \\
\hline
\end{tabular}

Table 7 Effect of dexamethasone on CLD at 36 weeks postmenstrual age: all trials

\begin{tabular}{|c|c|c|c|c|c|c|c|c|}
\hline Trials & Year & $\begin{array}{l}\text { Expected } \\
\text { observed }\end{array}$ & $\begin{array}{l}\text { Expected } \\
\text { total }\end{array}$ & $\begin{array}{l}\text { Controls } \\
\text { observed }\end{array}$ & $\begin{array}{l}\text { Controls } \\
\text { total }\end{array}$ & $E R R(95 \% C I)$ & $E R D(95 \% C I)$ & NNT $(95 \% C I)$ \\
\hline Durand et $a l^{34}$ & 1995 & 2 & 21 & 8 & 17 & $0.20(0.04,0.95)$ & $-37.54(-64.38,-10.69)$ & \\
\hline Brozanski et $a l^{35}$ & 1995 & 24 & 40 & 30 & 37 & $0.74(0.43,1.27)$ & $-21.08(-40.83,-1.34)$ & \\
\hline Yeh et $a l^{38}$ & 1994 & 3 & 47 & 11 & 47 & $0.27(0.08,0.98)$ & $-17.02(-31.00,-3.04)$ & \\
\hline Shinwell et $a l^{\beta 1}$ & 1996 & 15 & 132 & 11 & 116 & $1.20(0.55,2.61)$ & $1.88(-5.72,9.48)$ & \\
\hline Rastogi et $a b^{30}$ & 1996 & 0 & 32 & 6 & 32 & $0.08(0.00,1.49)$ & $-17.19(-31.38,-3.00)$ & \\
\hline Sander et $a l^{\beta 2}$ & 1994 & 4 & 17 & 5 & 14 & $0.66(0.18,2.45)$ & $-12.18(-44.38,20.01)$ & \\
\hline Tapia et $a l^{39}$ & 1996 & 3 & 55 & 12 & 54 & $0.25(0.07,0.87)$ & $-16.77(-29.38,-4.16)$ & \\
\hline Pooled $\left[\chi^{2}=11.05(\mathrm{df}=6)\right]$ & & 51 & 344 & 83 & 317 & $0.57(0.44,0.76)$ & $-9.41(-14.50,-4.32)$ & $10(6,23)$ \\
\hline
\end{tabular}

dexamethasone. The results suggest that eight infants would need to be treated with dexamethasone to prevent one infant developing CLD at 28 days in the overall analyses. In the subgroup where dexamethasone was started within 36 hours, ${ }^{30} 31333839$ the ERR and NNT were $0.64(0.49,0.83)$ and $8(5-16)$, respectively. The ERR and NNT of the subgroup where dexamethasone was started between 7 and 14 days $^{34-36}$ were $0.83(0.72,0.95)$ and 6 $(4,20)$, respectively. The findings in the surfactant subgroup 3031343539 did not differ from the overall analysis [ERR 0.73 (0.60$0.90)$ ]. There was significant heterogeneity in the results of the trials.

CLD AT 36 WEEKS OF POSTMENSTRUAL AGE In the neonates given dexamethasone, the overall analysis ${ }^{30-32} 343539$ showed a significant reduction in CLD (table 7). Similar results were obtained in the subgroup where surfactant ${ }^{30-32} 34353839$ was used [ERR 0.57 $(0.43,0.75)]$. In the subgroup analyses ${ }^{34} 35$ where dexamethasone was started between 7 and 14 days of age, the ERR was $0.63(0.47$, 0.85 ) and only three infants would need to be treated with dexamethasone to prevent one infant developing CLD. In the subgroup $^{30-333839}$ where dexamethasone was started within 36 hours of age the ERR was $0.53(0.33,0.83)$ and 13 infants would need to be treated to prevent one infant developing CLD. There was no heterogeneity in the results of the trials.

DEATH OR CLD AT 28 DAYS

There was a significant reduction in risk of death or CLD in the overall and in all three subgroup analyses in the dexamethasone group. In the overall analyses the ERR was 0.83 $(0.74,0.93)$ and the NNT was $8(5,17)$. The ERRs and NNTs of the subgroups where dexamethasone was begun within 36 hours and between 7 and 14 days of postnatal age were $0.83(0.71,0.97), 9(5,36)$, and $0.83(0.73$, 0.93), $9(5,60)$, respectively. The ERR and
NNT of the surfactant subgroup were 0.89 $(0.73,0.97)$ and $11(5,31)$, respectively.

DEATH OR CLD AT 36 WEEKS OF POSTMENSTRUAL AGE

The risk of death or CLD at 36 weeks postmenstrual age was significantly reduced in the overall analyses, ERR 0.78 (0.66, 0.93), NNT $9(5,25)$ and in the subgroup where dexamethasone was started between 7 and 14 days of postnatal age, ERR $0.60(0.44,0.81)$, NNT $3(2,7)$. Thus to reduce the incidence of death or CLD by one on an average, only three infants would need to be treated with dexamethasone, starting between 7 and 14 days of postnatal age. Results of the surfactant subgroup were similar to those of the overall analysis.

DAYS ON MECHANICAL VENTILATION

Table 8 shows that there is a decrease in days on mechanical ventilation in the overall as well as the subgroup analyses. Overall weighted mean difference with $95 \% \mathrm{CI},-2.05(-2.33$, -1.78 ). Only five studies s $^{30-32} 3539$ in the overall analyses, four studies ${ }^{30-32} 39$ in the subgroup where dexamethasone was started within 36 hours of age, and one study ${ }^{35}$ in the subgroup where dexamethasone was started between 7 and 14 days of age assessed this outcome. Four studies assessed this outcome in the surfactant subgroup. ${ }^{30} 323539$

DAYS ON OXYGEN

There was no significant decrease in the number of days on supplemental oxygen, (table 8 ) with the overall weighted mean difference being $0.66(-0.08,1.40)$. However, in the subgroup $^{35}$ where dexamethasone was started between 7 and 14 days there was a significant decrease in the days in supplemental oxygen, with the weighted mean difference being -59 $(-72,-46)$, but only one trial assessed this outcome in the subgroup. 
Table 8 Results: days on mechanical ventilation, in supplemental oxygen, in hospital, and days to regain birthweight

\begin{tabular}{lllll}
\hline & & \multicolumn{2}{l}{ Weighted mean difference $(95 \%$ CI) } & \\
\cline { 3 - 5 } & $\begin{array}{l}\text { No of patients } \\
\text { Dex/Controls }\end{array}$ & Dexamethasone begun 0-14 days & Begun <36 hours of age & Begun 7-14 days of age \\
\hline Days on MV & $277 / 262$ & $-2.05(-2.33,-1.78)^{30-32} 3539$ & $-2.03(-2.30,-1.76)^{30-32} 39$ & $-25(-33.57,-16.43)^{35}$ \\
Days in oxygen & $303 / 282$ & $0.66(-0.08,1.40)^{30-33} 3539$ & $0.87(0.12,1.61)^{30-33} 39$ & $-59(-71.74,-46.26)^{35}$ \\
Days in hospital & $204 / 186$ & $-2.06(-3.51,-1.68)^{31-33} 35$ & $-2.03(-2.96,-1.10)^{31-33}$ & $-25(-30.84,-19.16)^{35}$ \\
Days to regain birthweight & $58 / 52$ & $3.86(1.75,5.98)^{30} 33$ & $3.86(1.75,5.98)^{30} 33$ & - \\
\hline
\end{tabular}

DAYS IN HOSPITAL

There was a significant reduction in hospital stay in the group that received dexamethasone (table 8), which was evident in the overall as well as the subgroup analyses. Overall weighted mean difference with $95 \%$ CI was -2.06 $(-3.51,-1.68)$. Four studies ${ }^{31-33} 35$ in the overall analyses, three ${ }^{31-33}$ in the subgroup where dexamethasone was started within 36 hours of age, one study ${ }^{35}$ in the subgroup where dexamethasone was started between 7 and 14 days and two studies in the surfactant subgroup $^{32} 35$ assessed this outcome.

\section{DAYS TO REGAIN BIRTHWEIGHT}

Only two studies ${ }^{3033}$ have recorded this outcome. There was an increase in the number of days to regain birth weight in the group that received dexamethasone. The weighted mean difference was 3.9 days with a $95 \%$ CI of 1.8 , 6.0 days.

\section{HYPERTENSION}

There was a significant increased risk of hypertension in the group that received dexamethasone in the overall (table 9) and in the subgroup analyses where dexamethasone was started between 7 and 14 days of postnatal age: ERRs 3.04 (1.34, 6.86), $3.78(1.15,12.38)$ and NNHs $42(19,212) 65(16,344)$, respectively. In the surfactant subgroup there were no significant differences in risk of hypertension [ERR 1.91 $(0.84,4.35)]$. In all the trials that showed a significant increase, the hypertension was transient, with most patients recording normal blood pressures by day 10 of starting dexamethasone. None of the patients required continued anti-hypertensive treatment after treatment or at discharge.

\section{HYPERGLYCAEMIA}

The risk of hyperglycaemia due to dexamethasone was increased, but the risk was low and only just reached significance in the overall analyses, ${ }^{30} 311^{34-37} 39$ the ERR being 1.32 (1.04, $1,69)$ and NNH $14(8,100)$. This was not significant in the subgroup analyses: the ERRs were $1.34(0.94,1.91)$ and $1.30(0.93,1.83)$, respectively.
INTRAVENTRICULAR HAEMORRHAGE (ANY GRADE) The pooled results showed no significant difference in effect of dexamethasone on the incidence of IVH all grades and grades 3 or 4 in the overall ${ }^{30} 323539$ and subgroup analyses, the ERRs being $0.91(0.65,1.29)$ and $1.06(0.69$, $1.61)$, respectively.

RETINOPATHY OF PREMATURITY (ROP) ANY STAGE There was no significant difference in the incidence of ROP in the overall ${ }^{30-34} 363739$ or any subgroup analyses; the ERRs were 0.92 (0.67, $1.26), 0.86(0.57,1.30), 0.94(0.41,2.13)$ and $0.85(0.55,1.30)$, respectively.

NECROTISING ENTEROCOLITIS, AIR LEAK SYNDROMES, AND SEPSIS

Pooled estimates of NEC,,$^{30-35} 39$ air leak syndromes, ${ }^{30-32} 34353739$ and sepsis ${ }^{30-37} 39$ showed no significant difference; the ERRs being 0.64 $(0.37,1.12), 0.80(0.57,1.12)$ and $0.89(0.63$, 1.25). The results were similar in all the subgroup analyses.

\section{INSULIN TREATMENT}

Insulin treatment for hyperglycaemia as an outcome was assessed in two studies ${ }^{30}{ }^{32}$ : ERR $1.68(0.75,3.78)$

LONG TERM NEURODEVELOPMENTAL AND PULMONARY OUTCOMES

Cummings et $a \beta^{77}$ assessed neurodevelopmental outcomes at 6 and 15 months. At 15 months corrected age, none (0/9) of the survivors from the 42 day course of dexamethasone had abnormalities on neurological examination, whereas more than $56 \%$ (5/9) of the survivors from the 18 day group and $40 \%(2 / 5)$ of the survivors from the control group had marked truncal hypotonia or cerebral palsy. Thus good neurodevelopmental outcome (normal exam and Bayley indexes $>84$ ) were more often present in infants in the 42 day group (78\%) than in 18 day group $(22 \%)$ or the control group $(40 \%)$. Follow up at 4 years ${ }^{40}$ showed better results in the 42 day group on all the McCarthy subscales. The problem with long term pulmonary and neurodevelopmental outcome is that crossover was allowed in most of

Table 9 Effect of dexamethasone on hypertension: all trials

\begin{tabular}{|c|c|c|c|c|c|c|c|c|}
\hline Trials & Year & $\begin{array}{l}\text { Expected } \\
\text { observed }\end{array}$ & $\begin{array}{l}\text { Expected } \\
\text { total }\end{array}$ & $\begin{array}{l}\text { Controls } \\
\text { observed }\end{array}$ & $\begin{array}{l}\text { Controls } \\
\text { total }\end{array}$ & ERR $(95 \% C I)$ & $E R D(95 \% C I)$ & NNH $(95 \%$ CI $)$ \\
\hline Durand $e t a l^{4}$ & 1995 & 2 & 23 & 1 & 20 & $1.74(0.16,19.18)$ & $3.70(-11.27,18.66)$ & \\
\hline Brozanski et $a l^{35}$ & 1995 & 0 & 39 & 0 & 39 & $1.00(0.02,50.40)$ & $0.00(-4.99,4.99)$ & \\
\hline Cummings et $a l^{37}$ & 1989 & 0 & 12 & 0 & 11 & $0.92(0.02,46.20)$ & $-0.38(-17.09,16.34)$ & \\
\hline Kari et $a l^{36}$ & 1993 & 7 & 17 & 1 & 24 & $9.88(1.22,80.32)$ & $37.01(12.29,61.73)$ & \\
\hline Shinwell et $a l^{1}$ & 1996 & 8 & 132 & 2 & 116 & $3.52(0.75,16.55)$ & $4.34(-0.37,9.05)$ & \\
\hline Rastogi et $a l^{30}$ & 1996 & 1 & 36 & 1 & 34 & $0.94(0.06,15.10)$ & $-0.16(-7.98,7.65)$ & \\
\hline Tapia et al ${ }^{39}$ & 1996 & 3 & 55 & 2 & 54 & $1.47(0.25,8.81)$ & $1.75(-6.08,9.59)$ & \\
\hline Pooled $\left[\chi^{2}=3.7(\mathrm{df}=6)\right]$ & & 21 & 314 & 7 & 298 & $3.04(1.34,6.86)$ & $2.33(-0.47,5.13)$ & $42(19,212)$ \\
\hline
\end{tabular}


the trials following the study period. Recent trials have used shorter courses and smaller doses, so long term follow up from these trials would be valuable.

The sensitivity analyses were done to look at the effect of different doses and duration of dexamethasone treatment on mortality and CLD. Included in the analyses were all the trials which used dexamethasone in doses starting at $0.5 \mathrm{mg} / \mathrm{kg} /$ day for $7-14$ days. ${ }^{30} 33343639$ This was done to see if there were differences in outcomes when trials which used higher doses and longer courses were not included in the analyses. The results were similar to those of the overall analyses; the ERRs and NNTs for CLD at 28 days $^{30} 33343639$ and 36 weeks of postmenstrual age ${ }^{30} 34{ }^{39}$ were $0.57(0.45,0.73)$, $4(3,8)$, and $0.29(0.15,0.54), 5(4,10)$, respectively.

\section{Discussion}

This systematic review and meta-analyses of early dexamethasone to prevent CLD was based on the methods recommended by the Cochrane Collaboration. ${ }^{27}$ This involved an extensive search of published data and rigorous methodology. Reviewer bias was minimised by independent assessment and extraction of data by two authors. Where subgroup analyses were planned the criteria were established before the search or data analyses, in keeping with the initial objectives of the review.

There were some potential sources of bias in this systematic review. No attempt was made to trace unpublished trials. The small number of patients in the few trials reporting on outcomes such as days to regain birth weight, days in supplemental oxygen, and days in hospital, may affect the pooled results if no benefit or only a small effect due to lack of statistical power, rather than the absence of true effect is shown. On the other hand, some significant results such as increased risk of hypertension, which was transient, may be of doubtful clinical importance. Another limitation was the heterogeneity of the doses and duration of dexamethasone administration among the trials. However, this was addressed by sensitivity analyses.

In the overall pooled analysis of death ${ }^{30-39}$ there was no significant difference in risk when dexamethasone was administered. In the pooled subgroup ${ }^{34-37}$ where dexamethasone was started between 7 and 14 days, despite the small number of patients (91 patients in the intervention group and 94 in the control group), there was a significant reduction in risk of death, NNT $8(4,30)$. This significant finding has not been reported before. This difference in mortality between the groups does not seem to be due to differences in populations, but it cannot be precluded. The differences were derived from randomised controlled trials so the potential for bias is minimal.

There was a significant reduction in the risk of CLD both at 28 days and 36 weeks of postmenstrual age in both the overall analyses and all the subgroup analyses. The risk reduction at 36 weeks was greater when dexamethasone was started between 7 to 14 days of postnatal age [NNT $3(2,9)]$ : only three infants need to be treated with dexamethasone to prevent one infant developing CLD. In this subgroup only two of the four trials assessed this outcome and in one trial steroids were administered in pulses of three days out of every 10 until 36 weeks of postmenstrual age or until supplemental oxygen was no longer required. Three out of the four trials assessed CLD at 28 days in this subgroup. The findings of risk reduction, however, were consistent in all the trials except that of Shinwell $e t a l^{29}$ where the ERR was 1.17 (0.69, 1.99), which suggested a trend towards an increase in CLD if dexamethasone was administered. This finding was not significant, but this was the largest trial with 132 patients in the intervention group and 116 in the control group. The pooled results indicate that despite the increased risk in that trial there was still a significant risk reduction in the incidence of CLD both at 28 days and 36 weeks postmenstrual age in both the overall and the subgroup analyses. The reasons for the increased risk of CLD in the trial by Shinwell et $a l^{29}$ are unclear. They may be related to the dose, duration, or the timing of administration. The heterogeneity in the results of CLD at 28 days is due to the results of this trial. There was no significant difference in the continuous outcome such as days in supplemental oxygen, despite a significant reduction in CLD. This may be due to skewed data with wide standard deviations. It would be more appropriate to report these continuous variables with medians and ranges rather than means and standard deviations to derive more meaningful information from these continuous variables.

The pooled estimates showed an increased risk of hypertension in the overall and in the subgroup where dexamethasone was started within 7 to 14 days of age. The increased risk was significant as the NNH was $42(19,212)$ in the overall analysis. The hypertension tended to be transient and was more apparent in the trials that used dexamethasone for longer than 14 days as well as higher doses.

There was a significant increase in risk of hyperglycaemia with NNH $14(8,100)$. This shows the wide confidence intervals, reflecting the small number of patients assessed for this outcome and the lack of strong evidence.

The sensitivity analyses showed that when dexamethasone was administered for 7 to 14 days, starting at $0.5 \mathrm{mg} / \mathrm{kg} /$ day the results were similar to those of the overall analyses except that NNT were lower for CLD at 28 days and 36 weeks of postmenstrual age $[4(3,8), 5(3$, $9)]$. Thus it seems that lower doses and shorter duration of dexamethasone treatment may be as effective as longer courses. However this needs to be further tested in randomised controlled studies. It may even be possible to use smaller doses than those used in the current studies.

There are concerns that dexamethasone may reduce cerebral DNA accretion, causing functional impairment. ${ }^{20}$ One year follow up of 12 infants given only two doses of hydrocortisone at birth showed increased frequencies of 
neurological and electroencephalographic abnormalities. ${ }^{41}$ The shortcomings of most other trials are the subsequent treatment with dexamethasone in the control group after the study period. Thus it is difficult to get a true picture of the neurodevelopmental outcomes from these studies. Mammel et $a l^{42}$ followed up eight ventilator dependent infants treated with a three week course of dexamethasone; at 1 year they showed a small but non-significant reduction in the Bayley mental developmental index. Ohlsson ${ }^{43}$ found no difference in Bayley scores at 2 years of age in seven treated and nine control infants who were not crossed over. There was only one trial ${ }^{37}$ from this review that has published long term outcomes at 6,15 months, and 4 years. However, there were only $9 / 13,9 / 12$, and $5 / 11$ survivors in the 42 day, 18 day, and control groups, respectively. With animal data suggesting that dexamethasone may interfere with cerebral DNA accretion, and conflicting evidence from small number of follow up patients it is still not clear whether dexamethasone adversely affects long term neurodevelopmental outcomes and whether it is related to dose or duration of treatment.

The results of this review and the metaanalyses of early postnatal dexamethasone for prevention of CLD suggest a significant reduction in risk of CLD at 28 days and 36 weeks of postmenstrual age if dexamethasone is started within 14 days of postnatal age. However, if begun between 7 to 14 days of postnatal age there is also a dramatic reduction in risk of death as well as an increase in the magnitude of risk reduction of CLD. There is the potential of substantial differences in the populations being treated early and those being treated late and thus caution is warranted in interpreting the differences between the groups. The magnitude of effect is also greater in reducing CLD at 28 days and 36 weeks of postmenstrual age when administered for 7 to 14 days at doses starting from $0.5 \mathrm{mg} / \mathrm{kg} /$ day. The only side effects found that were clinically significant were transient hypertension, hyperglycaemia, and an increase in days to regain birthweight. The clinical importance of the increased risk was low (NNH) compared with the benefits (comparing the NNT). However caution is warranted in routine administration of dexamethasone at this stage despite the above results for the following reasons:

(1) There are no significant long term studies of neurodevelopmental outcomes, in infants who received dexamethasone. There are ongoing concerns about myelination and somatic growth with dexamethasone. There are no significant long term studies of neurodevelopmental outcomes in infants who received dexamethasone. Due to the lack of the above it is difficult to assess the risk benefit ratio of the dramatic reduction in mortality versus the long term neurodevelopmental outcome;

(2) The above studies used different doses and duration of dexamethasone administration, therefore it is not clear which would be the minimum effective dose;
(3) There are few studies stratified according to gestational age so it is difficult to identify the group who would benefit the most with acceptable side effects. However, it can be recommended that if it is deemed necessary to give dexamethasone, it can be started between $7-14$ days postnatal age in doses starting at $0.5 \mathrm{mg} / \mathrm{kg} /$ day and weaned over 7 to 14 days.

Future studies need to target infants most at risk of developing CLD. Stratification by gestational age would ensure that the most at risk group is targeted. Importantly, further studies to define the optimal dose and duration of dexamethasone are needed to reduce further the risk of side effects. Finally, long term neurodevelopmental and pulmonary outcomes of infants who received dexamethasone in optimal doses and not crossed over would need to be undertaken before dexamethasone could be recommended for routine administration to all at risk populations. Thus follow up should be inbuilt in all future primary studies.

1 Hennes HM, Lee MB, Rimm AA, Shapiro DL. Surfactant replacement therapy in respiratory distress syndrome. Meta-analyses of clinical trials of single dose surfactant extract. Am $\mathcal{F}$ Dis Child 1991;145:102-4.

2 Merritt TA, Hallman M, Bloom BT et al. Prophylactic treatment of very premature infants with human surfactant. $N$ Engl $\mathcal{F}$ Med 1986;315:785-90.

3 Kendig JW, Notter RH, Cox C, et al. Surfactant replacement therapy at birth. Final analyses of a clinical trial and comparisons with similar trials. Pediatrics 1988;82:756-62.

parisons with similar trials. Pediatrics 1988;82:756-62.
4 Jobe AH. Pulmonary surfactant therapy. $N$ Engl $f$ Med 1993;328:861-8.

5 Long W, Thompson T, Sundell H, et al. Effects of two doses of a synthetic surfactant on mortality rate and survival without bronchopulmonary dysplasia in 700-1350 gram infants with respiratory distress syndrome. $\mathcal{F}$ Pediatr 1991;118:595-605.

6 The OSIRIS Collaborative group. Early versus delayed neonatal use of synthetic surfactant-the judgment of OSIRIS Lancet 1992;340:1363-9.

7 Jobe AH, Mitchell BR, Gunkel JH. Beneficial effects of the combined use of prenatal corticosteroids and postnatal combined use of prenatal corticosteroids and postnatal surfactant on prete.

8 Ohlsson A, Calvert SA, Hosking M, Shennan AT. Randomised controlled trial of dexamethasone treatment in very-low-birth-weight infants with ventilator-dependent chronic lung disease. Acta Paediatr 1992;81:751-6.

9 Mammel MC, Johnson DE, Green TP, Thompson TR. Controlled trial of dexamethasone in infants with bronchopulmonary dysplasia. Lancet 1983;i:1356-8

10 Avery GB, Fletcher AB, Kaplan M, Brudno DS. Controlled trial of dexamethasone in respiratory-dependent infants with bronchopulmonary dysplasia. Pediatrics 1985;75:10611 .

11 Harkavy KL, Scanlon JW, Chowdhry PK, Grylack LJ. Dexamethasone therapy for chronic lung disease in ventilatoramethasone therapy for chronic lung disease in ventilator1989;115:979-83.

12 Collaborative Dexamethasone Trial group. Dexamethasone therapy in neonatal chronic lung disease: an international placebo-controlled trial. Pediatrics 1991;88:421-7.

13 Kramer LI, Hultzen C. The role of steroids in early bronchopulmonary dysplasia. Pediatr Res 1978; 12:564A.

14 Merritt TA, Stuard ID, Puccia J, et al. Newborn tracheal aspirate cytology: classification during respiratory distress syndrome and bronchopulmonary dysplasia. 7 Pediatr 1981;98:949-56.

15 Ogden B, Murphy S, Saunders G, Pathak D, Johnson J. Neonatal lung neutrophils and lastase/proteinase inhibitor imbalance. Am Rev Respir Dis 1984;130:817-21.

$16 \mathrm{McColm}$ J, McIntosh N. Tracheal IL8 as a predictor of chronic lung disease. Pediatr Res 1994;36:A153.

17 Groneck P, Opperman M, Speer CP. Levels of complement anaphylatoxin $\mathrm{C} 5 \mathrm{a}$ in pulmonary effluent fluid of infants at risk for chronic lung disease and effects of dexamethasone treatment. Pediatr Res 93;34:586-90.

18 Groneck P, Reuss D, Goetze-Speer B, Speer CP. Effects of dexamethasone on chemotactic activity and inflammatory mediators in tracheobronchial aspirates of preterm infants at risk for chronic lung disease. F Pediatr 1993;122:938-44.

$19 \mathrm{Ng}$ PC. The effectiveness and side effects of dexamethasone in preterm infants with bronchopulmonary dysplasia. Arch Dis Child 1993;68:330-6.

20 Weichsel ME. The therapeutic use of glucocorticoid hormones in the perinatal period. Potential neurological hazards. Ann Neurol 1977;2:364-6. 
$21 \mathrm{Ng}$ PC, Brownlee KG, Dear PR. Gastrointestinal perforation in preterm babies treated with dexamethasone for bron-

22 Werner JC, Sicard RE, Hansen TWR, et al. Hypertrophic cardiomyopathy associated with dexamethasone therapy fo bronchopulmonary dysplasia. 7 Pediatr 1992;120:286-91.

23 Ehrenkranz RA. Steroids, chronic lung disease and retinopathy of prematurity. Pediatrics 1992;90:646-7.

24 Wilson DM, Baldwin RB, Ariagano RL. A randomised, placebo-controlled trial of effects of dexamethasone on hypothalamic-pituitary-adrenal axis in preterm infants. $\mathcal{F}$ Pediatr 1988;113:764-8.

25 Mukwaya G. Immunosuppressive effects and infections associated with corticosteroid therapy. F Pediatr Infect Dis 1988;7:499-504

26 Tan KL. Blood pressure in very low birthweight infants in the first 70 days of life. $\mathcal{F}$ Pediatr $1988 ; 112: 266-70$

27 Cochrane Library [ database on disc and CD-ROM ]. The Cochrane Collaboration. Oxford Update Software. London: Cochrane Collaboration. Oxford

28 Sinclair JC, Bracken MB eds. Effective Care of Newborn Infant. New York: Oxford University Press, 1992.

29 Schultz KF, Chalmers I, Haynes RJ, Altman DG. Empirical evidence of bias; dimensions of methodologic quality associated with estimates of treatment effect in controlled clinical trials. $\mathcal{F} A M A$ 1995;273:408-12.

30 Rastogi A, Akintorin SM, Bez ML, Morales P, Pildes RS. A controlled trial of dexamethasone to prevent bronchopulmonary dysplasia in surfactant treated infants. Pediatrics 1996;98:204-10.

31 Shinwell ES, Karplus M, Zmora E, et al. Failure of early postnatal dexamethasone to prevent chronic lung disease in infants with respiratory distress syndrome. Arch Dis Child 1996;74:F33-7.

32 Sanders RJ, Cox C, Phelps DL, Sinkin RA Pediatr Res 1994;36:122-8.

33 Yeh TF, Torre JA, Rastogi A, Anyebuno MA, Pildes RS Early postnatal dexamethasone therapy in premature
infants with severe respiratory distress syndrome. A infants with severe respiratory distress syndrome. A
double blind, controlled study. F. Pediatr 1990;117:27382 .
34 Durand M, Sardesai S, McEvoy C. Effects of early dexamethasone therapy on pulmonary mechanics and chronic lung disease in very low birth weight infants. A randomised controlled trial. Pediatrics 1995; 95:584-90.

35 Brozanski BS, Jones JG, Gilmour CH, et al. Effect of pulse dexamethasone therapy on the incidence and severity of chronic lung disease in the very low birth weight infant. 7 Pediatr 1995;126:769-76.

36 Kari MA, Ikonen RS, Koivisto M, Raivio KO. Dexamethasone treatment in preterm infants at risk of bronchopulmonary dysplasia. Arch Dis Child 1993;68:566-9.

37 Cummings JJ, D’Eugenio DB, Gross SJ. A controlled trial of dexamethasone in preterm infants at high risk for bronchopulmonary dysplasia. $N$ Engl $\mathcal{f} \mathrm{Med}$ 1989;320:1505-10.

38 Yeh TF, Lin IJ, Sheih WS, et al. Prevention of chronic lung disease in premature RDS infants with early and prolonged dexamethasone therapy- a multicenter, doubleprolonged dexamethasone therapy- a multicenter,
blind controlled study. Pediatr Res 1994;36:262A.

39 Tapia JL, Ramirez R, Cifuentes J, et al. Effects of early dexamethasone administration on respiratory outcome in VLBW infants with respiratory distress syndrome treated with surfactant. Pediatr Res 1996;39:249A.

40 Gross SJ, Cummings JJ. Four year follow-up of a controlled trial of Dexamethasone in ventilator dependent preterm infants. Pediatr Res 1992;31:204A.

41 Fitzhardinge PM, Eisen A, Lejtenyi C, Metrakos K, Ramsay $M$. Sequelae of early steroid administration to the newborn infant. Pediatrics 1974;53:877-83.

42 Mammel MC, Fiterman C, Coleman M, Boros SJ. Short term dexamethasone therapy for bronchopulmonary dysplasia: acute effects and 1-year follow-up. Dev Pharmacol Ther. 1987;10:1-11.

43 Ohlsson A. A randomised controlled trial of dexamethasone treatment in very low birth weight infants with ventilatory dependent chronic lung disease. [MSc thesis.] 1990: McMaster University, Canada. 